Ciência Florestal, Santa Maria, v. 23, n. 3, p. 379-387, jul.-set., 2013

ISSN 0103-9954

\title{
ACÚMULO E DECOMPOSIÇÃO DA SERAPILHEIRA EM QUATRO FORMAÇÕES FLORESTAIS ${ }^{1}$
}

\author{
LITTER ACCUMULATION AND DECOMPOSITION IN FOUR DIFFERENT FOREST FORMATION
}

\author{
Felipe Vieira Cunha Neto ${ }^{2}$ Paulo Sérgio Santos Leles ${ }^{3}$ Marcos Gervasio Pereira ${ }^{4}$ \\ Vinicius Geraldo Helmeer Bellumath ${ }^{5}$ Jorge Makhlouta Alonso ${ }^{6}$
}

\begin{abstract}
RESUMO
O objetivo deste trabalho foi quantificar a serapilheira acumulada sobre o solo e sua taxa de decomposição, em quatro diferentes tipologias florestais: povoamentos de Acacia mangium wild, Mimosa artemisiana Heringer \& Paula e Eucalyptus grandis x Eucalyptus urophylla; e uma floresta secundária na fazenda Cachoeirão, no município de Além Paraíba, MG. Em cada formação florestal foram feitas duas avaliações, a primeira em junho de 2008 e a segunda em junho de 2009, o material foi levado para laboratório, sendo separado, seco em estufa e pesado. Para avaliação da decomposição da serapilheira, foram utilizados litter bags, sendo as coletas realizadas aos 30,60, 90, 150 e 210 dias após a instalação. O povoamento de eucalipto apresentou os maiores estoques nas duas coletas, enquanto mimosa (Mimosa artemisiana Heringer \& Paula) apresentou menores valores. A serapilheira de mimosa (Mimosa artemisiana Heringer \& Paula) apresentou a maior taxa de decomposição, com valores de $\mathrm{K}=0,0034 \mathrm{e} \mathrm{T}^{1 / 2}=203$ dias, enquanto para acácia (Acacia mangium wild) foram verificados menores valores $\left(\mathrm{K}=0,0013\right.$ e $\mathrm{T}^{1 / 2}=533$ dias). Dentre os povoamentos florestais, mimosa (Mimosa artemisiana Heringer \& Paula) e eucalipto (Eucalyptus grandis $\mathrm{x}$ Eucalyptus urophylla) produziram a serapilheira mais rapidamente decomposta, o que evidencia a melhor eficiência dessas espécies no processo de ciclagem de nutrientes e incorporação de matéria orgânica ao solo.
\end{abstract}

Palavras-chave: ciclagem de nutrientes; espécies florestais; recuperação do solo.

\footnotetext{
ABSTRACT

The aim of this study was to quantify the litter layer on the soil and its decomposition rate, in four different forest types: wild stands of Acacia mangium, Mimosa artemisiana Heringer \& Paula and Eucalyptus grandis x Eucalyptus urophylla, and a secondary forest at Fazenda Cachoeirão in the municipality of Além Paraíba, Minas Gerais state. In each forest formation, there were two evaluations, the first one in June 2008 and the second in June 2009, the material was taken to laboratory, where it was separated, oven-dried and weighed. For litter decomposition evaluation, litter bags were used, and those were collected at 30, $60,90,150$ and 210 days after the installation. In the eucalypt area it was observed the highest litter stock in both evaluations, and the lowest values occurred in mimosa area. The litter of mimosa had the highest rate of decomposition, with values of $\mathrm{K}=0.0034$ and $\mathrm{T}^{1 / 2}=203$ days, while acacia had the lowest $(\mathrm{K}=$

1 Parte da Dissertação de Mestrado do primeiro autor apresentado ao Programa de Pós-Graduação em Ciências Ambientais e Florestais, Universidade Federal Rural do Rio de Janeiro.

2 Engenheiro Florestal, Msc., Professor do Instituto Federal Educação, Ciências e Tecnologia, Av. Dos Ramires, Distrito Industrial, CEP 78000-200, Cáceres (MT). fvcneto@hotmail.com

3 Engenheiro Florestal, Dr., Professor Adjunto IV do Departamento de Silvicultura, Universidade Federal Rural do Rio de Janeiro, Rod BR 465, Km 7, CEP 23890-000, Seropédica (RJ).pleles@ufrrj.br

4 Engenheiro Agrônomo, Dr., Professor Associado IV do Departamento de Solos, Universidade Federal Rural do Rio de Janeiro, Rod BR 465, Km 7, CEP 23890-000, Seropédica (RJ). Bolsista do CNPq. mgervasiopereira01@gmail.com

5 Estudante de Engenharia Florestal, Universidade Federal Rural do Rio de Janeiro, Rod BR 465, Km 7 , CEP 23890-000, Seropédica (RJ).bellumath@yahoo.com.br

6 Engenheiro Florestal, Mestrando do Programa de Pós-Graduação em Ciências Ambientais e Florestais, Universidade Federal Rural do Rio de Janeiro, Rod BR 465, Km 7, CEP 23890-000, Seropédica (RJ). j_makh@hotmail.com

Recebido para publicação em 27/01/2011 e aceito em 15/05/2012
} 
0.0013 and $\mathrm{T}^{1 / 2}=533$ days). Among forest stands, mimosa and eucalypt produce faster decomposing litter, which highlights the best efficiency of these species in the process of nutrient cycling and incorporation of organic matter in soil.

Keywords: nutrient cycling; forest species; soil recovery.

\section{INTRODUÇÃO}

Em termos de área, o Brasil possui $60,7 \%$ do seu território coberto por florestas naturais e apenas $0,8 \%$ de plantações florestais, que correspondem a aproximadamente 6,6 milhões de hectares, de acordo com as informações do ano de 2009 (ABRAF, 2010). Destas plantações, espécies dos gêneros Eucalyptus e Pinus representam 93\% do total e Acacia mearnsii e Acacia mangium, juntas, 2,75\% (ABRAF, 2009). Esses números evidenciam o quanto o Brasil pode expandir a sua área cultivada por espécies florestais, seja para fins produtivos ou conservacionistas. O Brasil apresenta larga extensão de terras em processo erosivo, muitas dessas se localizam em regiões de terreno acidentado e que poderiam ser utilizadas para plantios florestais. Espécies florestais, normalmente, são menos exigentes quanto à qualidade do solo em comparação aos cultivos agrícolas. Outro aspecto importante é a comprovada rentabilidade da produção florestal bem planejada (VALE, 2004; BIANQUINI, 2008).

As árvores exercem importante papel sobre os sistemas em que estão inseridas. Ao longo do crescimento e desenvolvimento, a vegetação arbórea adiciona matéria orgânica ao solo via deposição de serapilheira e renovação do sistema radicular, exercendo influência sobre os atributos físicos do solo tais como a densidade, porosidade, aeração, capacidade de infiltração e retenção de água, bem como a formação e estabilização dos agregados. $\mathrm{O}$ componente arbóreo também influencia a ciclagem de nutrientes e por consequência na fertilidade do solo, além de promover um microclima que favorece o desenvolvimento de diversos organismos.

A serapilheira compreende, principalmente, o material de origem vegetal (folhas, flores, ramos, cascas e sementes) e, em menor proporção, o de origem animal (restos animais e material fecal) depositado na superfície do solo. É um dos indicadores de recuperação de áreas degradadas, sendo adicionada via vegetação e, sendo posteriormente decomposta e suprindo o solo e as raízes com nutrientes e com matéria orgânica (MARTINS, 2009).

O clima das regiões tropicais úmidas, normalmente, proporciona uma média elevada da produção de biomassa florestal, havendo elevada demanda por nutrientes. A dinâmica e a magnitude da contribuição na ciclagem, pela redistribuição de nutrientes, é variável no ecossistema florestal. A produção de serapilheira, decomposição e rápida ciclagem de nutrientes, são processos dinâmicos que dão aos solos sob florestas, características peculiares (GAMA-RODIGUES, 2007).

Quantidades significativas de nutrientes podem retornar ao solo pela deposição de componentes senescentes da parte aérea de plantas e sua posterior decomposição (TOLEDO et al., 2002). Segundo Arato et al. (2003), elevada taxa de decomposição da serapilheira indica favorecimento de rápida liberação e o consequente reaproveitamento dos nutrientes por parte do sistema radicular da vegetação. A ciclagem dos nutrientes depende de vários fatores, dentre os quais, a sua mobilidade no interior da planta. Nutrientes como $\mathrm{N}, \mathrm{P}, \mathrm{K}$ e $\mathrm{Mg}$ são considerados móveis e o Ca imóvel (NEVES et al., 2001).

A concentração e o conteúdo de nutrientes na serapilheira variam em função do tipo de solo, da vegetação, da densidade populacional, da habilidade da espécie em absorver, utilizar e redistribuir os nutrientes, do habitat natural e da idade das árvores. A deposição varia conforme a espécie, idade das árvores e o tipo de floresta (plantada ou natural), entre outros fatores (NEVES et al., 2001). A serapilheira acumulada sobre o solo é um indicador de qualidade ambiental, pois representa um estoque de nutrientes para futura mineralização e ciclagem (SILVA, 2006).

Sabendo da importância que a serapilheira possui para o acúmulo de matéria orgânica, reserva de nutrientes e na manutenção da atividade biológica em solos altamente intemperizados, nada mais vantajoso que a introdução, nesses ambientes (degradados ou não), de espécies que possam não apenas mitigar os efeitos da degradação do solo, mas dar condições para que o processo de sucessão vegetal ocorra com sucesso (BALIEIRO et al., 2004a).

Em face do exposto, o objetivo desse trabatho foi quantificar a serapilheira acumulada sobre o solo, sua taxa de decomposição e seu conteúdo de 
nutrientes, em quatro diferentes tipologias vegetais, sendo elas: povoamentos homogêneos de Acacia mangium wild, Mimosa artemisiana Heringer \& Paula e Eucalyptus grandis x Eucalyptus urophylla; e uma floresta secundária na fazenda Cachoeirão, no município de Além Paraíba, MG.

\section{MATERIAL E MÉTODOS}

$\mathrm{O}$ estudo foi conduzido na fazenda Cachoeirão, no município de Além Paraíba, estado de Minas Gerais, no período de abril de 2008 a junho de 2009. A área encontra-se na latitude $21^{\circ} 56$ '53.52”S e longitude $42^{\circ} 53$ '40.42”O. A altitude média é de $390 \mathrm{~m}$. A precipitação média anual da região é de $1.390 \mathrm{~mm}$, com período seco compreendido entre os meses de junho a setembro. A temperatura média anual é de $22,30^{\circ} \mathrm{C}$, sendo a média das máximas anual de $28,30^{\circ} \mathrm{C}$ e a média das mínimas anual de $16,30^{\circ} \mathrm{C}$. A topografia da região é acidentada com relevo forte ondulado e montanhoso, observa-se nessa paisagem o predomínio de Cambissolos Háplicos. A cobertura vegetal, natural da região, segundo Veloso et al. (1991), classifica-se como Floresta Estacional Semidecidual.

Foram avaliadas quatro áreas, todas com 3 anos e meio de plantio: plantio de Acacia mangium Wild; plantio de Mimosa artemisiana Heringer \& Paula; plantio de Eucalyptus grandis $\mathrm{x}$ Eucalyptus urophylla (Eucalyptus urograndis) e floresta secundária.

Segundo Fonseca (2005), os plantios de acácia e mimosa foram realizados em dezembro de 2004, em área com declividade média em torno de $20 \%$. Na fase de produção de mudas, ambas as espécies foram inoculadas com fungos micorrízicos arbusculares (FMAs) e estirpes de rizóbio. A área era coberta por vegetação de gramíneas. O plantio dessas espécies, adotando o espaçamento $2 \times 2 \mathrm{~m}$, foi organizado em forma de mosaico, sendo que cada unidade componente corresponde a um quadrado de $8 \times 8$ metros, onde foram abertas 16 covas de plantio. Este arranjo de plantio foi estabelecido para a realização do trabalho de Fonseca (2005), cujo objetivo era verificar a sobrevivência e o crescimento inicial destas duas espécies, oriundas de mudas produzidas em três tipos de recipientes.

Foram abertas covas de $30 \times 30 \times 30 \mathrm{~cm}$ e aplicado $100 \mathrm{~g}$ de fosfato de Araxá por cova. $\mathrm{Na}$ manutenção, realizaram-se dois coroamentos (60 e 150 dias após o plantio) e o controle das formigas cortadeiras. O objetivo deste plantio foi re- verter o processo de degradação e recuperar a área.

O povoamento de eucalipto, com área de aproximadamente 8,0 hectares, foi formado na mesma época e em área ao lado ao plantio de acácia e mimosa, tendo como objetivo a produção de madeira. O espaçamento de plantio adotado foi de 2,5 x 2,0 metros, sendo aplicados, na adubação de plantio, 150 gramas de N-P-K (04-31-04) por cova. Este adubo contém fosfato natural reativo, com $31 \%$ de $\mathrm{P}_{2} \mathrm{O}_{5}$ total, sendo $11 \% \mathrm{P}_{2} \mathrm{O}_{5}$ solúvel em água e $18 \%$ de $\mathrm{P}_{2} \mathrm{O}_{5}$ solúvel em ácido cítrico, além de $22 \%$ de $\mathrm{Ca}, 0,1 \%$ de $\mathrm{Cu}$ e $0,3 \%$ de $\mathrm{Zn}$. A área destinada ao experimento com eucalipto localiza-se em área anexa a do povoamento em mosaico de acácia e mimosa.

Segundo informações de moradores mais antigos da Fazenda, a área de floresta secundária era, anteriormente, uma pastagem de capim-gordura (Melinis minutiflora P. Beauv.) e foi abandonada há aproximadamente 40 anos, ocorrendo um processo de sucessão secundária. Um levantamento fitossociológico realizado por Lima (2005) concluiu que este trecho da floresta estudada se encontra em estádio inicial de sucessão. A área de estudo localiza-se próximo ao limite com o povoamento de eucalipto, numa área com dimensões aproximadas $20 \times 20$ metros.

Para a avaliação da serapilheira, foi feita a amostragem do material acumulado sobre o solo, em cada uma das áreas. Foram realizadas duas coletas, sendo a primeira em junho de 2008 e a segunda um ano após (junho de 2009). Em ambas as áreas, foi utilizado um gabarito de $1 \times 1 \mathrm{~m}$ para realização das coletas, sendo recolhidas quatro repetições, em cada época, estas foram alocadas de forma sistemática. A coleta foi realizada retirando todo o material vegetal na área do gabarito. As amostras foram acondicionadas em sacos plásticos e identificadas.

No laboratório, o material coletado foi seco ao ar e triado nas frações folhas, galhos e material reprodutivo, e posteriormente levado à estufa de circulação de ar forçada onde permaneceu por 48 horas a $65^{\circ} \mathrm{C}$. Em seguida, as amostras foram pesadas em balança, obtendo assim o peso seco por $\mathrm{m}^{2}$, sendo este valor transformado para hectare (ha).

Para avaliar as taxas de decomposição nos sistemas estudados foram utilizados 15 litter bags, que consistiram em sacolas de polivinil com malha de $2 \mathrm{~mm}$ e dimensões de $25 \times 25 \mathrm{~cm}$. Em cada litter bag foram colocadas 10 gramas de folhas da serapilheira acumulada sobre o piso florestal, sendo selecionado o material em menor grau de decomposição. 
Para a confecção destes litter bags foram utilizadas amostras de material seco ao ar. Para a obtenção da massa seca correspondente, foi gerado um fator de correção obtido pela secagem em estufa de circulação de ar forçada a $65^{\circ} \mathrm{C}$ de $10 \mathrm{~g}$ de material úmido. Sendo que o material permaneceu em estufa de até atingir massa constante. De posse da massa seca obtida, foi possível gerar um fator de correção a fim de converter a massa úmida inicial de folhas dos litter bags em massa seca. Esse procedimento foi realizado para a serapilheira de cada área em estudo.

Os litter bags foram distribuídos aleatoriamente na superfície do solo e coletados aos 30, 60, 90,150 e 210 dias após a instalação dos mesmos. Em cada área e para cada época de coleta foram depositados três litter bags (repetições).

Após a coleta, os litter bags foram levados ao laboratório, onde o material remanescente (não decomposto) foi limpo. Utilizou-se um pincel para a retirada da terra que estava aderida à serapilheira remanescente, para que não houvesse interferência na pesagem da amostra. Em seguida, esse material foi colocado em estufa de circulação de ar forçada a $65^{\circ} \mathrm{C}$, até atingir peso constante, e pesados em balança de precisão.

A taxa de decomposição da serapilheira foi calculada pela expressão: massa remanescente $(\%)=$ (massa final / massa inicial) x 100.

Após o cálculo da massa remanescente ao longo do período, a constante de decomposição $\mathrm{k}$ foi calculada, segundo Thomas; Asakawa (1993), com o modelo exponencial:

\section{$\mathrm{Xt}=\mathrm{Xo} \cdot e-\mathrm{kt}$,}

Em que:

$\mathrm{Xt}=$ peso do material seco remanescente após t dias; e Xo = peso do material seco colocado nos litter bags no tempo zero $(\mathrm{t}=0)$.

O tempo de meia-vida $\left(\mathrm{t}_{1 / 2}\right)$ foi calculado segundo Rezende et al. (1997):

$$
\mathrm{T}^{1 / 2}=\ln (2) / \mathrm{K}
$$

Em que: $\mathrm{K}=$ constante de decomposição calculada pela fórmula anterior $\left(\mathrm{Xt}=\mathrm{Xo} . \mathrm{e}^{-\mathrm{kt}}\right)$.

Os dados foram submetidos à ANOVA, obedecendo às predisposições para a realização de tal análise. Em seguida, realizou-se o teste de médias de Tukey.

\section{RESULTADOS E DISCUSSÃO}

\section{Biomassa de serapilheira acumulada}

Na Tabela 1 verifica-se que na primeira co- leta (junho de 2008), foram quantificadas maiores quantidades de serapilheira acumulada nos povoamentos de eucalipto e acácia, sendo que esses não diferiram estatisticamente entre si. A floresta secundária diferiu estatisticamente do povoamento de eucalipto e não dos demais. O menor acúmulo de serapilheira foi verificado no povoamento de mimosa.

Padrão similar no tocante ao acúmulo de serapilheira nas diferentes tipologias vegetais foi verificado na segunda coleta (junho de 2009). O estoque de serapilheira na área de eucalipto apresentou maior valor, seguido da área de acácia e da área de floresta secundária. $\mathrm{O}$ povoamento de mimosa, nesta segunda avaliação, apresentou menor valor de serapilheira acumulada, não diferindo estatisticamente do valor observado para a floresta secundária.

Comparando-se as duas coletas realizadas, pode-se constatar que, no geral, os valores de serapilheira acumulada são maiores na segunda coleta, o que pode ser justificado pelo crescimento das plantas e evolução dos povoamentos.

Em avaliação do plantio puro de Acacia mangium aos 5 anos de idade sobre um Argissolo Vermelho-Amarelo, em Seropédica - RJ, Balieiro et al. (2004a) encontraram valores de $12,7 \mathrm{Mg} \mathrm{ha}^{-1}$ de estoque de serapilheira, valor esse superior ao encontrado para essa espécie no presente trabalho, o que pode ser atribuído às diferentes condições climáticas entre as duas localidades.

Para a fração foliar, o mesmo padrão foi observado nas duas coletas, sendo os maiores acúmulos verificados nos povoamentos de eucalipto e acácia, diferindo dos menores valores que foram observados para a mata secundária e mimosa.

Em cada época de coleta, valores seguidos de mesma letra na mesma coluna não diferem entre si pelo teste de Tukey $(\mathrm{P}<0,05)$. * Não realizada análise estatística.

Em relação à fração galhos, na primeira coleta houve maior quantidade no povoamento de eucalipto, sendo que os valores não diferiram dos observados na área de mata secundária. As demais tipologias apresentaram valores mais baixos não diferindo entre si. $\mathrm{O}$ alto valor observado na primeira coleta, para a fração galhos na área de floresta secundária, ocorreu devido à presença de um ramo de diâmetro considerável da espécie angico-vermelho na amostra.

Na segunda coleta, a fração galhos apresentou padrão semelhante, sendo novamente verificado maior acúmulo no povoamento de eucalipto, seguido pela floresta secundária. Nessa coleta foi consta- 
TABELA 1: Estoques de serapilheira $\left(\mathrm{Mg} \mathrm{ha}^{-1}\right)$, em duas épocas, em quatro formações florestais, em Além Paraíba, MG.

TABLE 1: Litter fall stocks $\left(\mathrm{Mg} \mathrm{ha}^{-1}\right)$ in two seasons, in four different forest formations, in Além Paraíba, Minas Gerais state.

\begin{tabular}{ccccc}
\hline Formação Florestal & Folhas & Galhos & $\begin{array}{c}\text { Material } \\
\text { Reprodutivo* }\end{array}$ & Total \\
\hline \multicolumn{5}{c}{ junho de $2008(3,5$ anos após o plantio dos povoamentos $)$} \\
\hline Eucalyptus urograndis & $5,89 \mathrm{a}$ & $2,94 \mathrm{a}$ & 0,000 & $8,83 \mathrm{a}$ \\
Acacia mangium & $6,08 \mathrm{a}$ & $0,31 \mathrm{~b}$ & 0,000 & $6,39 \mathrm{ab}$ \\
Floresta secundária & $1,72 \mathrm{~b}$ & $2,10 \mathrm{a}$ & 0,000 & $3,82 \mathrm{bc}$ \\
Mimosa artemisiana & $2,14 \mathrm{~b}$ & $0,22 \mathrm{~b}$ & 0,000 & $2,36 \mathrm{c}$ \\
\hline \multicolumn{5}{c}{ junho de 2009 (4,5 anos após o plantio dos povoamentos $)$} \\
\hline Eucalyptus urograndis & $7,97 \mathrm{a}$ & $5,45 \mathrm{a}$ & 0,000 & $13,42 \mathrm{a}$ \\
Acacia mangium & $6,43 \mathrm{a}$ & $0,36 \mathrm{c}$ & 0,059 & $6,85 \mathrm{~b}$ \\
Floresta secundária & $3,05 \mathrm{~b}$ & $1,57 \mathrm{~b}$ & 0,089 & $4,71 \mathrm{bc}$ \\
Mimosa artemisiana & $1,64 \mathrm{~b}$ & $0,72 \mathrm{c}$ & 0,000 & $2,36 \mathrm{c}$ \\
\hline
\end{tabular}

Valores seguidos de mesma letra coluna, para cada coleta, não diferem entre si $(\mathrm{p}<0,05)$ pelo teste de Tukey.

tada diferença significativa entre os valores observados nas duas tipologias, sendo também verificada diferença no acúmulo de galhos nas áreas de acácia e de mimosa, sendo os valores observados nessas áreas semelhantes entre si.

Os maiores valores verificados para a deposição da fração galhos no povoamento de eucalipto podem ser explicados pelo fato de que em idades entre 3 e 5 anos existe tendência de maior desrama natural em plantas desse gênero (FONSECA, 1979). Em trabalho de Balieiro et al. (2004b), foi verificada uma maior quantidade de serapilheira acumulada sobre o solo de povoamento de Eucalyptus grandis $\left(11,84 \mathrm{Mg} \mathrm{ha}^{-1}\right)$ quando comparado a plantios de Pseudosamanea guachapele. Os autores observaram que a elevada contribuição de material lenhoso na composição da serapilheira de Eucalyptus grandis aumentou o tempo médio de decomposição do material no solo, promovendo desta forma um maior acúmulo deste.

Na primeira coleta não foi identificada presença da fração material reprodutivo nas tipologias estudadas. Já na segunda, verificou-se a ocorrência dessa fração na área de floresta secundária e no povoamento de acácia. A escassez dessa fração para os povoamentos implantados pode ser justificada pelo fato de que nestes plantios, ainda não foi atingida a idade reprodutiva plena, para a área de mata secundária, atribui-se o observado à ausência de espécies com estruturas reprodutivas.

A fração folhas, na primeira coleta, foi a que mais contribuiu para a formação do estoque de serapilheira para as áreas em estudo, com exceção da área de floresta secundária com $45 \%$ de folhas e $55 \%$ de galhos. As áreas que apresentaram maiores frações de folhas acumuladas foram acácia (95\%) e mimosa (90\%), seguidas de eucalipto (64\%) e floresta secundária $(45 \%)$.

$\mathrm{Na}$ segunda coleta (Figura 1) observa-se, sem exceção, um maior percentual da fração folhas nos estoques de serapilheira de todas as áreas estudadas. A área que apresentou o maior acúmulo percentual de folhas foi a de acácia (94\%), seguida de mimosa (65\%), floresta secundária $(65 \%)$ e eucalipto $(59 \%)$. Como a quantidade de material reprodutivo quantificada nos estoques de serapilheira foi baixa e ocorreu apenas no povoamento de acácia e na floresta secundária, estas não foram incluídas no cálculo do percentual.

Estudos têm demonstrado contribuição acima de $60 \%$ da fração folhas na composição da serapilheira (KINDEL et al., 2004; FERNANDES et al., 2006; FERREIRA et al., 2007; SOARES et al., 2008), fato constatado também pelo presente estudo, excetuando-se o observado para mata secundária na primeira coleta.

Os teores e estoques de nutrientes na serapilheira estão expressos na Tabela 2. Houve diferença significativa de teores de $\mathrm{N}$ entre as áreas estudadas, sendo que as áreas de floresta secundária e mimosa assemelharam-se, apresentando os maiores teores de N, em ambas as avaliações. Observa-se, portanto, que as áreas com as serapilheiras de maiores teores de $\mathrm{N}$ são também aquelas com os menores estoques deste nutriente na serapilheira. Tal fato pode ser explicado pelos menores estoques totais de serapi- 
TABELA 2: Teores e estoques de nutrientes na serapilheira, em povoamentos de Acacia mangium (acácia), Mimosa artemisiana (mimosa), Eucalyptus grandis x Eucalyptus urophylla (eucalipto) e floresta secundária, em Além Paraíba, MG.

TABLE 2: Litter nutrient and stocks on the stands of Acacia mangium (acacia), Mimosa artemisiana (mimosa), Eucalyptus grandis $x$ Eucalyptus urophylla (eucalypt) and secondary forest in Além Paraíba, Minas Gerais state.

\begin{tabular}{|c|c|c|c|c|c|c|}
\hline Coleta & Cobertura & $\mathrm{N}$ & $\mathrm{P}$ & K & $\mathrm{Ca}$ & $\mathrm{Mg}$ \\
\hline & florestal & ---- & --------- & - teor $(\mathrm{g}$ & 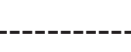 & ----- \\
\hline \multirow{4}{*}{ Junho 2008} & Acácia & $9,14 \mathrm{~b}$ & $0,28 \mathrm{~b}$ & $0,34 \mathrm{a}$ & $2,47 \mathrm{~b}$ & $1,02 \mathrm{~b}$ \\
\hline & Floresta & $13,85 \mathrm{a}$ & $0,35 \mathrm{~b}$ & $0,46 \mathrm{a}$ & $5,19 \mathrm{a}$ & $2,44 \mathrm{a}$ \\
\hline & Eucalipto & $7,77 \mathrm{~b}$ & $0,38 \mathrm{~b}$ & $0,47 \mathrm{a}$ & $2,89 \mathrm{~b}$ & $0,72 \mathrm{~b}$ \\
\hline & Mimosa & $13,52 \mathrm{a}$ & $0,56 \mathrm{a}$ & $0,46 \mathrm{a}$ & $1,31 \mathrm{~b}$ & $1,09 \mathrm{~b}$ \\
\hline \multirow{4}{*}{ Junho 2009} & Acácia & $12,36 \mathrm{ab}$ & $0,22 \mathrm{~b}$ & $0,46 \mathrm{a}$ & $3,44 \mathrm{~b}$ & $1,20 \mathrm{bc}$ \\
\hline & Floresta & $15,01 \mathrm{a}$ & $0,53 \mathrm{a}$ & $0,34 \mathrm{a}$ & $6,93 \mathrm{a}$ & $2,78 \mathrm{a}$ \\
\hline & Eucalipto & $6,80 \mathrm{~b}$ & $0,33 \mathrm{~b}$ & $0,23 \mathrm{a}$ & $3,26 \mathrm{~b}$ & $0,72 \mathrm{c}$ \\
\hline & Mimosa & $14,21 \mathrm{a}$ & $0,47 \mathrm{a}$ & $0,34 \mathrm{a}$ & $4,51 \mathrm{~b}$ & $1,52 \mathrm{~b}$ \\
\hline \multicolumn{7}{|c|}{----------------------------- estoque $\left(\mathrm{kg} \mathrm{ha}^{-1)}\right.$----------------- } \\
\hline \multirow{4}{*}{ Junho 2008} & Acácia & $59,6 \mathrm{a}$ & $1,8 \mathrm{~b}$ & $2,1 \mathrm{~b}$ & $16,0 \mathrm{~b}$ & $6,9 \mathrm{ab}$ \\
\hline & Floresta & $51,8 \mathrm{a}$ & $1,4 \mathrm{~b}$ & $1,8 \mathrm{~b}$ & $19,0 \mathrm{~b}$ & $9,3 \mathrm{a}$ \\
\hline & Eucalipto & $68,1 \mathrm{a}$ & $3,3 \mathrm{a}$ & $4,1 \mathrm{a}$ & $25,8 \mathrm{a}$ & $6,4 \mathrm{ab}$ \\
\hline & Mimosa & $32,7 \mathrm{~b}$ & $1,3 \mathrm{~b}$ & $1,1 \mathrm{~b}$ & $3,4 \mathrm{c}$ & $2,7 \mathrm{~b}$ \\
\hline \multirow{4}{*}{ Junho 2009} & Acácia & $88,8 \mathrm{a}$ & $1,5 \mathrm{~b}$ & $3,1 \mathrm{a}$ & $23,9 \mathrm{~b}$ & $8,4 \mathrm{ab}$ \\
\hline & Floresta & $70,8 \mathrm{a}$ & $2,5 \mathrm{~b}$ & $1,4 \mathrm{~b}$ & $33,9 \mathrm{~b}$ & $13,0 \mathrm{a}$ \\
\hline & Eucalipto & $92,1 \mathrm{a}$ & $4,5 \mathrm{a}$ & $3,3 \mathrm{a}$ & $44,4 \mathrm{a}$ & $9,6 \mathrm{ab}$ \\
\hline & Mimosa & $31,0 \mathrm{~b}$ & $1,0 \mathrm{~b}$ & $0,9 \mathrm{~b}$ & $10,7 \mathrm{c}$ & $3,6 \mathrm{~b}$ \\
\hline
\end{tabular}

Valores seguidos de mesma letra coluna, para cada coleta, não diferem entre si $(p<0,05)$ pelo teste de Tukey.

lheira nesses ambientes, em comparação às áreas de eucalipto e acácia (Tabela 1). Também, verifica-se que, a serapilheira de maior teor de $\mathrm{N}$ (mimosa) é a que apresenta a maior taxa de decomposição $\left(\mathrm{T}^{1 / 2}\right)$. Maiores teores de $\mathrm{N}$ e menor relação $\mathrm{C} / \mathrm{N}$ implicam em maior velocidade de decomposição, conforme mencionado por Aita e Giacomini (2003) e Silva (2007). Quanto ao estoque de N na serapilheira, os povoamentos de eucalipto, acácia e floresta secundária apresentaram, em sequência, os maiores valores, tanto na primeira quanto na segunda avaliação. A área de plantio de mimosa apresentou o menor estoque desse nutriente. Ferreira et al. (2007) atribuíram a grande deposição de $\mathrm{N}$ em bosque de Mimosa caesalpiniaefolia à fixação biológica de nitrogênio. Dentre as espécies florestais desse estudo que fazem fixação biológica de $\mathrm{N}_{2}$ (Mimosa artemisiana e Acacia mangium), somente a mimosa se diferiu estatisticamente do povoamento de eucalipto.

Avaliando uma floresta de sucessão secundária e plantios homogêneos de Mimosa caesalpiniaefolia e Carapa guianensis (ambos com presença de regeneração natural), Fernandes et al.
(2006) verificaram maior aporte anual de nitrogênio pela serapilheira dos plantios em comparação à floresta. Segundo os autores, esse padrão pode ter sido influenciado, em parte, pela presença de plantas leguminosas encontradas naquelas áreas com capacidade de formação de associações com bactéria fixadoras de $\mathrm{N}_{2}$.

Quanto aos teores de fósforo, verificou-se diferença estatística entre as épocas de avaliação. Na primeira avaliação observaram-se maiores valores para a área de mimosa seguida, respectivamente, de eucalipto, floresta secundária e acácia que foram semelhantes. Na segunda avaliação, as áreas de floresta secundária e de mimosa igualaram-se, apresentando os maiores teores, sendo seguidas pelas áreas de eucalipto e acácia, as quais não apresentaram diferença significativa entre si. Também houve diferença estatística quanto aos estoques de $\mathrm{P}$ na serapilheira nas duas coletas, com destaque para a área de eucalipto, que superou as demais. Para as outras áreas, verificou-se padrão similar, sendo que a área de mimosa apresentou os menores valores absolutos.

Para os teores de $\mathrm{K}$, não se verificou dife- 
rença estatística em nenhuma das duas avaliações, já para o estoque de $\mathrm{K}$, foram observadas diferenças estatísticas entre as avaliações, em função da quantidade de serapilheira depositada. A área de eucalipto apresentou o maior valor na primeira avaliação. $\mathrm{Na}$ segunda coleta, os maiores valores de $\mathrm{K}$ ocorreram na área de acácia assemelhando-se à área de eucalipto.

Quanto ao Ca, observou-se diferença estatística entre as coletas. A floresta secundária se isolou em ambas as épocas, com os maiores valores, seguida dos três povoamentos florestais, que foram semelhantes entre si. Os estoques desse nutriente na serapilheira também apresentaram diferença estatística entre as duas coletas. Os maiores valores de estoque foram verificados na área de eucalipto, nas duas avaliações, seguidos das áreas de floresta secundária e acácia, que foram semelhantes. Os menores valores foram verificados na área de mimosa.

Os teores de $\mathrm{Mg}$ também apresentaram diferença significativa em ambas as avaliações. $\mathrm{Na}$ primeira, a área de floresta secundária apresentou maiores valores, não sendo observadas diferenças entre as demais. Para a segunda avaliação, o mesmo padrão foi observado, sendo que a área de eucalipto apresentou o menor valor, não diferindo estatisticamente da área de acácia. Quanto aos estoques de $\mathrm{Mg}$, tanto na primeira quanto na segunda avaliação, a área de floresta secundária e a de mimosa apresentaram, respectivamente, o maior e o menor valor estatístico. Já as áreas de acácia e de eucalipto apresentaram valores intermediários, não se diferindo das demais.

\section{Decomposição da serapilheira}

Na Figura 1, observam-se as curvas que representam o padrão de decomposição da serapilheira nas formações florestais ao longo do tempo. Verifica-se que a serapilheira de acácia foi a que apresentou a menor taxa de decomposição e mimosa a maior, ao longo dos 210 dias de estudo. A constante de decomposição (K) e o tempo de meia-vida $\left(T^{1 / 2}\right)$ da serapilheira são apresentadas na Tabela 3. Verifica-se menor constante $\mathrm{K}$ para acácia $(0,0013)$, seguida da área de floresta secundária $(0,0026)$, eucalipto $(0,0028)$ e mimosa $(0,0034)$. $\mathrm{O}$ maior tempo de meia-vida obtido foi para a área de acácia (533 dias), seguida da área de floresta secundária (266 dias), eucalipto (247 dias) e mimosa (203 dias). O elevado tempo de meia-vida encontrado para a área de acácia, bem como o reduzido va-

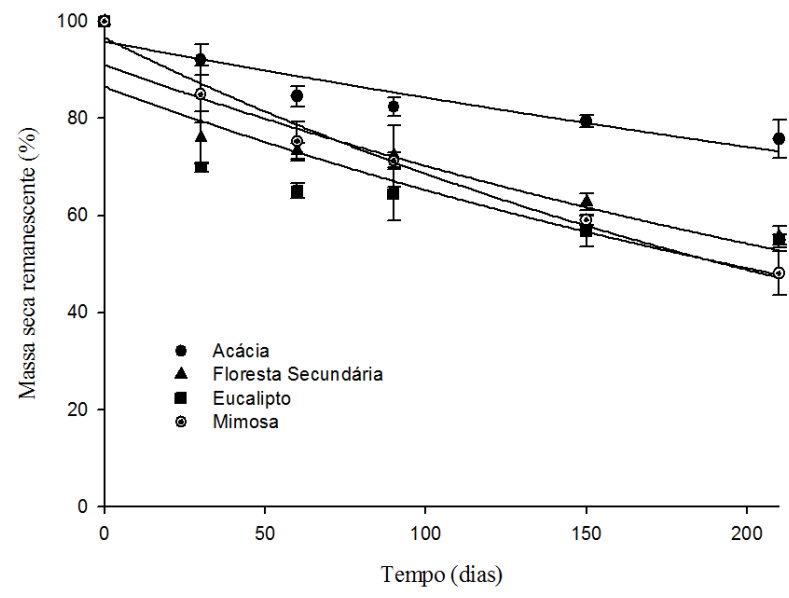

FIGURA 1: Curvas de decomposição da serapilheira (baseada na fração folhas) nos povoamentos de Acacia mangium (acácia), Mimosa artemisiana (mimosa), Eucalyptus grandis $\mathrm{x}$ Eucalyptus urophylla (eucalipto) e Floresta Secundária, em Além Paraíba, MG.

FIGURE 1: Litter decomposition curves (based on leaves) on stands of Acacia mangium (acacia), Mimosa artemisiana (mimosa), Eucalyptus grandis $x$ Eucalyptus urophylla (eucalypt) and secondary forest in Além Paraíba, Minas Gerais state.

TABELA 3: Constante de decomposição (K) e tempo de meia-vida $\left(\mathrm{T}^{1 / 2}\right)$ da serapilheira dos povoamentos de Acacia mangium (acácia), Mimosa artemisiana (mimosa), Eucalyptus grandis $\mathrm{x}$ Eucalyptus urophylla (eucalipto) e Floresta Secundária, em Além Paraíba, MG.

TABLE 3: Decomposition constant (K) and halflife $\left(\mathrm{T}^{1 / 2}\right)$ of the litter on the stands of Acacia mangium (acacia), Mimosa artemisiana (mimosa), Eucalyptus grandis $x$ Eucalyptus urophylla (eucalypt) and secondary forest in Além Paraíba, Minas Gerais state.

\begin{tabular}{cccc}
\hline Cobertura vegetal & $\mathrm{K}$ & $\mathrm{T}^{1 / 2}$ & $\mathrm{R}^{2}$ \\
\hline & $\mathrm{g} \mathrm{g} \mathrm{dia}^{-1}$ & $($ dias $)$ & \\
\hline Acácia & 0,0013 & 533 & 0,87 \\
Floresta & 0,0026 & 266 & 0,84 \\
Eucalipto & 0,0028 & 247 & 0,80 \\
Mimosa & 0,0034 & 203 & 0,98 \\
\hline
\end{tabular}


lor para constante de decomposição $(\mathrm{K})$, explicam o acúmulo da fração foliar nessa área. Cabe ressaltar que a taxa de decomposição foi baseada, exclusivamente, na decomposição da fração folhas.

Os dados obtidos para decomposição da serapilheira de mimosa justificam o baixo acúmulo verificado. $\mathrm{Na}$ área de povoamento de eucalipto, onde as folhas apresentaram decomposição relativamente rápida, os maiores valores de estoque podem ser decorrentes do intenso aporte de serapilheira verificado na área.

Também é possível inferir que, dentre povoamentos florestais, o de mimosa seria o mais eficiente na ciclagem de nutrientes, uma vez que a decomposição da serapilheira foliar dessa área ocorre de forma mais acelerada do que a dos outros povoamentos, o que pode implicar em uma mais rápida liberação de nutrientes para o solo e posterior absorção pela vegetação. Tal fato é de suma importância em áreas de solos de baixa fertilidade.

A elevada taxa de decomposição da serapilheira de mimosa, em comparação às outras áreas, pode ser atribuída, ao menor tamanho das folhas e consequente maior superfície específica, o que pode facilitar a ação dos organismos decompositores, visto que as folhas dessa espécie são recompostas, possuindo pequenos folíolos.

Fernandes et al. (2006) verificaram que, de modo geral, áreas com presença de leguminosas arbóreas apresentam maior velocidade de decomposição da serapilheira, sendo que esse padrão não foi verificado para a acácia, nesse estudo. Em plantios florestais para reabilitação de áreas de empréstimo, na Ilha da Madeira (RJ), Valente et al. (2005) constataram que os plantios com a presença de Acacia auriculiformes e Acacia mangium em sua composição, apresentaram menor potencial de decomposição do material decíduo em comparação com áreas onde o plantio foi realizado sem essas espécies.

Analisando a decomposição de filódios (folhas modificadas) de Acacia mangium, Balieiro et al. (2004a), atribuíram o grande acúmulo de serapilheira sobre o solo à baixa velocidade de decomposição dos filódios. Os autores encontraram valores de $\mathrm{K}=0,00165$ e $^{1 / 2}=421$ dias, sendo estes elevados, assim como os encontrados no presente trabalho.

\section{CONCLUSÃO}

Para os povoamentos de eucalipto e acácia, observou-se maior recobrimento do solo pela sera- pilheira aportada, proporcionando maior proteção ao mesmo.

As tipologias de mimosa (Mimosa artemisiana Heringer \& Paula) e eucalipto (Eucalyptus grandis x E. urophylla) apresentaram decomposição da serapilheira mais acelerada, o que evidência a melhor eficiência dessas espécies no processo de ciclagem de nutrientes e incorporação de matéria orgânica ao solo.

Os teores de nutrientes na serapilheira variaram conforme a tipologia, sendo o maior estoque de nutrientes observado na serapilheira do povoamento de eucalipto.

\section{REFERÊNCIAS BIBLIOGRÁFICAS}

ABRAF. Anuário estatístico da ABRAF - ano base 2009. www.abraf.com.br. Acessado em 15/05/10. ARATO, H. D.; MARTINS, S. V.; FERRARI, S. H. de S. Produção e decomposição de serapilheira em um sistema agroflorestal implantado para recuperação de área degradada em Viçosa-MG. Revista Árvore. v.27, n.5, p.715-721, 2003.

BALIEIRO, F. de C. et al. Acúmulo de nutrientes na parte aérea, na serapilheira acumulada sobre o solo e decomposição de filódios de Acacia mangium Willd. Ciência Florestal, v. 14, n .1, p. 59-65, 2004a.

BALIEIRO, F. de C. et al. Dinâmica da serapilheira e transferência de nitrogênio ao solo, em plantios de Pseudosamanea guachapele e Eucalyptus grandis. Pesquisa Agropecuária Brasileira, v. 39, n. 6, p. 597-601, 2004b.

BIANQUINI, L. A. Análise de custo e receita de povoamento de Eucalyptus grandis Hill ex Maiden submetidos a dois regimes de manejo: estudo de caso em propriedade rural na zona da Mata Mineira. 2008. 35 f. Monografia (Graduação em Engenharia Florestal) - Universidade Federal Rural do Rio de Janeiro, 2008.

FERNANDES, M.M. etal.Aportee decomposiçãode serapilheira em áreas de floresta secundária, plantio de sabiá (Mimosa caesalpiniaefolia Benth.) e andiroba (Carapa guianensis Aubl.) na Flona Mário Xavier, RJ. Ciência Florestal, v. 16, n. 2, p. 163175, 2006.

FERREIRA, R. L. C. et al. Deposição e acúmulo de matéria seca e nutrientes em serapilheira em um bosque de sabiá (Mimosa caesalpiniifolia Benth.). Revista Árvore, v. 31, n. 1, p. 7-12, 2007.

FONSECA, F. de A. Produção de mudas de Acacia mangium Wild. e Mimosa artemisiana 
Heringer \& Paula, em diferentes recipientes, utilizando compostos de resíduos urbanos, para a recuperação de áreas degradadas. 2005, $61 \mathrm{f}$. Dissertação (Mestrado em Ciências Ambientais e Florestais) - Universidade Federal Rural do Rio de Janeiro, 2005.

FONSECA, S. M. Implicações técnicas e econômicas na utilização da desrama artificial. Circular técnica IPEF, v. 1, n. 46, p. 1-22, 1979.

GAMA-RODRIGUES, A. C. da; BARROS, N. F. De; COMERFORD, N. B. Biomass and nutrient cycling in pure and mixed stands of native tree species in southeastern Bahia, Brazil. Revista Brasileira de Ciência do Solo, v. 31, n. 9, p. 287298, 2007.

KINDEL, A. et al. Dinâmica da decomposição da serapilheira em plantios de seringueira e em fragmento de Mata Atlântica - Minas Gerais. Rio de Janeiro : Embrapa Solos, 2004. 26 p. - (Embrapa Solos. Boletim de Pesquisa; n. 53)

LIMA, R. de M. Estrutura de um trecho de floresta estacional semidecidual no munícipio de Além Paraíba - MG. Monografia (Conclusão de Curso em Engenharia Florestal)- Universidade Federal Rural do Rio de Janeiro, 2005. 22 p.

MARTINS,S.V.Recuperaçãodeáreas degradadas: ações em áreas de preservação permanente, voçorocas, taludes rodoviários e de mineração. Viçosa: Aprenda Fácil, 2009. 270 p.

NEVES, E. J. M.; MARTINS, E. G.; REISSMANN, C. B. Deposição de serapilheira e de nutrientes de duas espécies da Amazônia. Boletim de Pesquisa Florestal, v. 7, n. 43, p. 47-60, 2001.

REZENDE, J. L. P. et al. Decomposição de folhas de Dalbergia nigra e de Eucalyptus grandis incubadas em terra de mata e de eucaliptal. In: SIMPÓSIO
NACIONAL DE RECUPERAÇÃO DE ÁREAS DEGRADADAS: DO SUBSTRATO AO SOLO, 3 ., 1997, Ouro Preto. Anais... Ouro Preto: SOBRADE : UFV/DEF, 1997. p. 136-143.

SILVA, M. S. C. DA. Indicadores de qualidade do solo em sistemas agroflorestais em Paraty, RJ. 2006, 54 f. Dissertação (Mestrado em Agronomia - Ciência do Solo) - Universidade Federal Rural do Rio de Janeiro, 2006.

SOARES, I. et al. Produção de serapilheira e ciclagem de nutrientes na cultura do cajueiro anão precoce. Revista Árvore, v. 32, n. 1, p. 173181, 2008.

THOMAS, R. J.; ASAKAWA, N. M. Decomposition of leaf litter from tropical forage grasses and legumes. Soil Biology and Biochemistry, v. 25, n. 10 , p. 1351-1361, 1993.

TOLEDO, L. de O.; PEREIRA, M. G.; MENEZES, C. E. G. Produção de serapilheira e transferência de nutrientes em florestas secundárias localizadas na região de Pinheiral, RJ. Ciência Florestal, v. 12, n. 2, p. 9-16, 2002.

VALE, R. S. Agrossilvicultura com eucalipto como alternativa para o desenvolvimento sustentável da Zona da Mata de Minas Gerais. 2004, 101 f. Tese (Doutorado em Ciência Florestal) Universidade Federal de Viçosa. Viçosa, 2004.

VALENTE, F. D. W. et al. Produção e decomposição de serrapilheira em medidas biológicas de reabilitação de áreas de empréstimo na Mata Atlântica. Revista Universidade Rural. Série Ciências da Vida, v. 25, n. 1, p. 18-25, 2005. VELOSO, H. P., RANGEL FILHO, A. L. R.; LIMA, J. C. A. Classificação da vegetação brasileira, adaptada a um sistema universal. Rio de Janeiro: IBGE, 1991. 123 p. 